Курза Н.В

\title{
ПРОБЛЕМЫ СУДЕБНОГО ТОЛКОВАНИЯ ПОЛОЖЕНИЙ АДМИНИСТРАТИВНЫХ РЕГЛАМЕНТОВ ПРИ ОСУЩЕСТВЛЕНИИ АДМИНИСТРАТИВНОГО СУДОПРОИЗВОДСТВА
}

\begin{abstract}
Аннотация: Предметом исследования является судебная практика по делам об оспаривании положений административных регламентов. В связи с вступлением в силу Кодекса административного судопроизводства РФ она находится в стадии становления, вследствие чего можно видеть преобразование судебного толкования при разрешении споров по делам, возникающим из публичных правоотношений. Административные регламенты устанавливают порядок осуществления отдельных видов государственного контроля, и в этом качестве могут ограничивать права и законные интересы граждан и организаций. Объект исследования составляют общественные отношения, возникающие в сфере защиты прав и свобод граждан в судебном порядке. Автор подробно рассматривает особенности административных регламентов как нормативных правовых актов. Научная новизна исследования определяется авторским подходом к установлению правовой природы административных регламентов, а также к выявлению предпосылок повышения правового качества этих нормативных документов. Обобщии практику Конституционного Суда РФ и Верховного РФ, автор вносит ряд предложений, направленных на оптимизацию преодоления пробелов в административных регламентов средствами судебного толкования. Основные выводы по результатам исследования затрагивают проблематику повышения эффективности административного судопроизводства.
\end{abstract}

Ключевые слова: Нормативный правовой акт, правовое регулирование, административный регламент, суд, административное судопроизводство, правовая определенность, конституиионный контроль, судебное толкование, административный иск, государственная услуга.

Abstract: The subject of this research is the judicial practice in cases that challenge the provisions of administrative regulations. In connection with the entry into force of the Administrative Procedure Code of the Russian Federation the practice is in its infancy, and we can see the transformation of the judicial interpretation of disputes in cases arising from public relations. Administrative Regulations establish the procedures for the implementation of certain types of state control, and as such, may limit the rights and legal interests of citizens and organizations. The object of this research is public relations arising in the sphere of protection of the rights and freedoms of citizens in the courts. The author carefully examines the features of the administrative regulations as regulatory legal acts. The scientific novelty of this research is substantiated by the author's approach to the establishment of the legal nature of administrative regulations, as well as identification of the prerequisites for increasing the quality of these legal regulations. Summarizing the practice of the Constitutional Court of the Russian Federation and the Supreme Court, the author makes a number of proposals aimed at optimization of overcoming gaps in administrative regulations by means of judicial interpretation. Key findings of the study concern the issues of increase of efficiency of the administrative proceedings.

Keywords: Constitutional control, legal certainty, administrative jurisdiction, court, administrative regulations, legal regulation, normative legal act, judicial interpretation, administrative claim, public service.

ктуальность рассмотрения проблем судебного толкования положений административных регламентов при осуществлении административного судопроизводства может быть обоснована следующими положениями. Во-первых, установленный порядок осуществления административного судопроизводства сформировался постепенно и подвергался существенным изменениям, итогом которых стало принятие Кодекса административного судопроизводства РФ. Его положения еще не в полном объеме получили научное осмысление. Во-вторых, до настоящего времени не получила разрешения дискуссия от- носительно природы административных регламентов и их места в иерархии нормативных правовых актов. В-третьих, в судебной практике имеются противоречия, возникающие при осуществлении толкования положений административных регламентов во взаимосвязи с нормами действующего законодательства.

Согласно ст. 118 Конституции РФ, судебная власть может осуществляться посредством административного судопроизводства. Кодекс административного судопроизводства РФ вступил в силу с 15 сентября 2015 г. В перечень разрешаемых судами административных дел включены дела об оспаривании норма- 
тивных правовых актов полностью или в части (п. 1 ч. 2 ст. 1 КАС РФ). Предмет таких исков составляют нормативные правовые акты, законодательное определение которых в России отсутствует. Поэтому судебное толкование этого понятия, сформулированное в правовых позициях Конституционного и Верховного судов РФ, имело большое значение для определения признаков нормативного акта.

Конституционный Суд РФ и Верховный Суд РФ дали в целом идентичное толкование дефиниции «нормативный правовой акт». Это позволяет утверждать, что высшие суды России формируют единую практику применения законодательства.

Так, Конституционный Суд РФ нормативным правовым актом признает рассчитанный на многократное применение акт общего действия, адресованный неопределенному кругу лиц. В нем должны содержаться общие правила или нормативные предписания, установленные от имени государства и обязательные для исполнения [1]. Если в отношении законов проблема выявления этих признаков не возникает, то в части ведомственных нормативных актов ситуация может кардинально отличаться из-за меньшей степени правовой определенности. Поэтому Конституционный Суд РФ исходит из признания легальности ведомственных нормативных актов. Это предполагает установление не противоречащего закону нормативного предписания (общего правила). Кроме того, необходимо оценить степень соблюдения надлежащего порядка принятия и обнародования, а также формы, в которую должен быть облечен нормативный акт [2]. В данном постановлении Конституционный Суд РФ создал условия для толкования ведомственных нормативных актов в части установления критерия правовой определенности и соответствия акту более высокой юридической силы. Кроме того, он обратил внимание на то, что содержание ведомственного нормативного акта подразумевают и определенную форму, в которой он подготавливается и принимается.

В свою очередь, Пленум Верховного Суда РФ указал на следующие признаки нормативного правового акта: направленность на урегулирование общественных отношений либо на изменение (прекращение) существующих правоотношений, возможность неоднократного применения, издание в установленном порядке управомоченным субъектом, наличие правил поведения, обязательных для неопределенного круга лиц [3]. В данном случае были созданы условия для судебного толкования положений ведомственных нормативных актов в системе регулирования отдельных общественных отношений.
Выявленным критериям должны соответствовать все нормативные правовые акты, принятые в действующей системе правового регулирования. В их иерархии особое место занимают ведомственные нормативные акты, которые издаются на основании положений закона и должны полностью соответствовать им. Видом ведомственных нормативных актов являются административные регламенты органов исполнительной власти, поскольку их содержание полностью отвечает признакам нормативного акта. Их появление в системе ведомственных нормативных актов стало следствием проведения административной реформы [4, с. 335]. Достоинством административных регламентов является их унифицированная структура (ст. 12 Федерального закона от 27 июля 2010 г. № 210Ф3 «Об организации предоставления государственных и муниципальных услуг»). Административными регламентами регулируется достаточно большая группа общественных отношений. Кроме того, часть административных регламентов определяет особенности исполнения отдельных государственных функций, предоставленных ведомству как органу исполнительной власти. При исполнении государственных функций реализуются, в том числе, полномочия по выявлению и пресечению правонарушений, привлечении виновных лиц к ответственности.

В связи с этим положения административных регламентов могут быть предметом административного иска об оспаривании нормативных правовых актов полностью или в части. Имеющаяся практика Верховного Суда РФ и Конституционного Суда РФ позволяет выявить некоторые проблемы, влияющие на судебное толкование положений административных регламентов.

Во-первых, в результате судебного толкования может устанавливаться, что в административных регламентах имеются случаи неверного толкования положений федерального законодательства. При этом норма закона подменяется произвольным толкованием, сформулированным в них. Рассматривая дело с подобной фабулой, суд может признать созданное предписание незаконным. И решение суда может в таком случае быть способом преодоления существующего действительного пробела, или же в нем может быть сформулирована правовая позиция, выявляющая соответствующий закону вариант применения правовой нормы (при наличии мнимого пробела). Например, Верховным Судом РФ проверялось положение Административного регламента МВД России, согласно которому лицо, желающее продлить срок действия разрешения на хранение оружия, обязано предоставить документ 
об изучении им правил безопасного обращения с оружием [5]. Удовлетворяя заявление, суд указал, что Федеральный закон «Об оружии» возлагает эту обязанность на лиц, впервые обращающихся за таким разрешением. В свою очередь, Федеральный закон «Об организации предоставления государственных и муниципальных услуг» запрещает требовать от заявителей такие документы, которые находятся в распоряжении государственных органов [6]. Иными словами, судом было установлено избыточное возложение ведомственным нормативным актом обязанности на гражданина. При этом нормативное положение, оспоренное в суде, нельзя признать пробельным; скорее, это расширительное толкование закона. И суд в данном случае констатировал его несоответствие закону. В результате судебного толкования были обеспечены интересы не только заявителя по настоящему делу, но и неопределенного круга лиц.

Во-вторых, достаточно часто в суде выявляется, что положения административных регламентов основаны на федеральном законе с иным предметом регулирования. Например, Административный регламент исполнения государственной функции по контролю и надзору за соблюдением участниками дорожного движения требований в области безопасности дорожного движения (утвержден приказом МВД России от 2 марта 2009 г. № 185) обжаловался заявителем в связи с предполагаемыми противоречиями этого акта Кодексу РФ об административных правонарушениях. Отказывая в удовлетворении заявления, Верховный Суд РФ указал, что положения КоАП РФ, действительно, не устанавливают правил составления схемы дорожно-транспортного происшествия, однако требуют подробной фиксации обстоятельств этого события. Способом фиксации выступает составление схемы, порядок чего и установлен положениями регламента. При этом суд использовал ссылку на положения Федерального закона «О полиции», ст. 12 которого требует от сотрудников полиции документировать обстоятельства совершения административного правонарушения. Иными словами, несмотря на то, что положения регламента применяются при осуществлении производства по делу об административном правонарушении, сам он как документ, устанавливающий порядок исполнения должностных обязанностей сотрудников полиции, основан не на положениях КоАП РФ, а на положениях другого федерального закона [7]. В данном случае судебное толкование положений административного регламента способствовало уяснению того, в развитие норм какого именно акта более высокой юридической силы он принимался.
В-третьих, в результате судебного толкования может быть выявлено, ограничивают ли положения административных регламентов права и свободы граждан, предусмотренные федеральным законодательством. Например, предметом рассмотрения Верховным Судом РФ стали положения Административного регламента по предоставлению государственной услуги по регистрации автомототранспортных средств и прицепов к ним (утвержден приказом МВД России от 7 августа 2013 № 605). В частности, оспаривались правила отказа в предоставлении государственной услуги в случае выявления признаков подделки идентификационной маркировки номерных агрегатов автомобиля, а равно при наличии сведений о его нахождения в розыске. Согласно позиции заявителя, эти нормы ограничивают права собственника владеть, пользоваться и распоряжаться принадлежащим ему имуществом. Отказывая в удовлетворении заявления, Верховный Суд РФ указал, что названные положения основаны на п. 1 ч. 1 ст. 13 ст. Федерального закона «О полиции», предоставляющего ей право запрещать эксплуатацию таких транспортных средств [8]. Таким образом, гражданско-правовое регулирование в данном случае не является приоритетным, поскольку сущностью государственной услуги, урегулированной административным регламентом, выступает осуществление административных процедур. В результате судебного толкования была уточнена правовая природа регистрационных действий.

И наконец, толкование, данное Конституционным Судом РФ, может быть положено в основу административного регламента, вследствие чего имеет место комбинированное преодоление и восполнение пробелов в законодательстве. Существование пробелов в праве является характеристикой правовой реальности. Сфера социальной жизни чрезвычайно многообразна, поэтому невозможно заранее предусмотреть все жизненные ситуации, в которых может возникнуть потребность в правовом регулировании [9, с. 17]. Эволюция общественных отношений может иметь более быстрые темпы, нежели процедура установления их правового регулирования [10, с. 129-145]. Признавая справедливость этих утверждений, можно обратиться к практике Конституционного Суда РФ.

Так, в постановлении от 2 февраля 1998 г. № 2-П Конституционный Суд РФ отметил, что срок регистрации гражданина по месту временного пребывания поставлен нормативным актом Правительства РФ в зависимость от усмотрения административных органов. Кроме того, неконституционным было признано установление оснований отказа в регистрации 
по месту пребывания и месту жительства [11]. В указанном постановлении не предусматривалось механизма приведения нормативного акта в соответствие с изложенной правовой позицией. Вследствие этого Правила регистрации и снятия граждан РФ с регистрационного учета по месту пребывания и по месту жительства в пределах РФ [12] продолжали действовать за исключением трех пунктов, признанных неконституционными. Указанные пункты получили новую редакцию, но только в 2002 г., например, было сформулировано правило, что регистрация по месту пребывания осуществляется на период, определенный соглашением сторон [13]. Правила действуют до настоящего времени, и на их основе принят Административный регламент ФМС России, содержащий последовательность административных процедур, необходимых для регулирования правоотношений в сфере регистрационного учета граждан по месту жительства или временного пребывания [14]. Таким образом, в данном случае в отсутствие нормативного регулирования имеющийся пробел в законодательстве был преодолен правовой позицией органа конституционного контроля и восполнен в результате юридической деятельности высшего органа исполнительной власти и в результате принятия ведомственного нормативного акта. Толкование, данное Конституционным Судом РФ, оказалось полностью востребованным в положениях административного регламента ФМС России.

Определенную специфику имеет практика арбитражных судов и судов общей юрисдикции, которые вносят существенный вклад в формирование механизма выявления пробелов в содержании нормативных актов. При этом толкование положений административных регламентов производится судами во взаимосвязи с правовой оценкой действий (бездействия) должностных лиц государственных органов. Кроме того, на формирование этой практики оказывают влияние правовые позиции высших судебных инстанций. И наконец, спорные отношения, становящиеся предметом судебного разбирательства, во многом соотносятся с положениями административных регламентов.

Например, в практике судов общей юрисдикции имеются судебные решения, защищающие законные интересы собственников имущества. Так, в суде общей юрисдикции гражданином обжаловались бездействия сотрудников РЭО ГИБДД, выразившиеся в отказе в регистрации транспортного средства, маркировка которого имела признаки видоизменения. Для совершения регистрационных действий гражданином был предъявлен договор купли-продажи и паспорт транспортного средства с отметками о наличии из- менений в идентификационную маркировку; автомобиль не состоял на учете как похищенный. При таких обстоятельствах суд произвел толкование положений Административного регламента МВД России по предоставлению государственной услуги по регистрации автомототранспортных средств и прицепов к ним следующим образом. Административный регламент содержит исчерпывающий перечень оснований для отказа в предоставлении государственной услуги. В заключении должностного лица, обжаловавшегося гражданином, ни одно из этих оснований не приведено, что может препятствовать повторному обращению заявителя за предоставлением этой услуги. Иными словами, из положений регламента не следует, что отказ в регистрации транспортного средства возможен в тех случаях, когда его идентификационные номера подвергались изменениям, но это установлено и отмечено в паспорте транспортного средства [15]. Такое решение суда не только способствовало восстановлению нарушенных прав заявителя, но и стало своеобразным прецедентом, защищающим интересы других добросовестных приобретателей имущества.

Достаточно интересно развивается судебное толкование положений административных регламентов в тех случаях, когда оно производится при рассмотрении дел об административных правонарушениях. Например, рассматривая жалобу гражданина на назначение ему штрафа за превышение скорости, суд установил, что ограничение скоростного режима было произведено в нарушение положений Административного регламента исполнения государственной функции по контролю и надзору за соблюдением участниками дорожного движения требований в области обеспечения безопасности дорожного движения (утвержден приказом МВД России от 2 марта 2009 г. № 185). Суд пришел к выводу, что состояние участка дороги, на котором было совершено инкриминируемое заявителю нарушение, не требовало ограничения скоростного режима. Кроме того, суд признал незаконным применение средств автоматической фиксации [16]. В другом деле судом было вынесено решение в пользу лица, привлекавшегося к административной ответственности, на основании того, что в деле отсутствовали сведения о соблюдении надлежащего порядка использования средств автоматической фиксации [17]. Таким образом, судебное толкование положений административных регламентов позволяет избежать неправомерного привлечения граждан к административной ответственности.

В свою очередь, в практике арбитражных судов можно выделить ряд решений, защищающих законные интересы взыскателей в сфере исполнительного 
производства. При этом можно отметить их взаимосвязь с толкованием положений административных регламентов, произведенным Верховным Судом РФ. Например, в 2009 г. Верховный Суд РФ признал незаконным отказ в приеме и рассмотрении заявлений взыскателей. В данном случае речь шла об обращении взыскания на средства федерального бюджета по денежным обязательствам бюджетных учреждений в случаях, когда средства на их лицевых счетах отсутствуют [18]. Указанные правовые позиции использовались арбитражными судами ряда федеральных округов в ходе правовой оценки действий судебных приставов-исполнителей (например, Федеральным арбитражным судом Волго-Вятского округа по делу № A11-14175/2009, ответчиком по которому было признано бюджетное учреждение). Из этого можно сделать вывод о том, что толкование, произведенное судом высшей инстанции, развивается судами при рассмотрении конкретных дел.

Оценивая соответствие действий должностных лиц органов исполнительной власти положениям административных регламентов, суды обеспечивают надлежащий порядок осуществления административных процедур. В связи с этим на административный орган могут быть возложены дополнительные обязанности. Например, рассматривая жалобу на бездействие администрации областного центра при решении вопроса о предоставлении земельного участка, суд возложил на ответчика обязанность принять постановление о предварительном согласовании места размещения объекта, утверждающее схему расположения земельного участка на кадастровом плане. Такой вывод был сделан судом на основании толкования положений административного регламента, определяющего последовательность административ- ных процедур при оказании муниципальных услуг, связанных с предоставлением земельных участков гражданам [19].

В заключение необходимо сделать следующие выводы. Во-первых, административные регламенты гармонично вошли в систему ведомственных нормативных актов благодаря соответствию общим признакам нормативных правовых актов. В связи с унифицированной структурой административные регламенты могут использоваться для регулирования значительной группы отношений, возникающих в публично-правовой сфере. Поэтому максимально востребованными они оказались в установлении порядка исполнения государственных функций и правил предоставления государственных услуг. Вовторых, для административного регламента, как и для иных ведомственных нормативных актов, характерно появление пробелов. Причинами их появления выступает сложная структура отношений, входящих в предмет правового регулирования, вследствие чего во многих случаях не представляется возможным сразу определить их правовую природу. В-третьих, восполнение и преодоление этих пробелов может эффективно осуществляться посредством судебного толкования при рассмотрении административных исков об оспаривании положений административных регламентов. При этом повышение эффективности работы судов будет способствовать подготовке и принятию административных регламентов, полностью соответствующих действующему законодательству. Предпосылками этого является унифицированная структура административных регламентов и предмет правового регулирования, разграниченный между вопросами осуществления государственных функций и правилами предоставления государственных услуг.

\section{Библиография:}

1. Постановление Конституционного Суда РФ от 17.11.1997 № 17-П по делу о проверке конституционности постановлений Государственной Думы Федерального собрания Российской Федерации от 21 июля 1995 г. № 1090-1 ГД «О некоторых вопросах применения Федерального закона «О внесении изменений и дополнений в Закон Российской Федерации «О статусе судей в Российской Федерации»» и от 11 октября 1996 г. № 682-II ГД «О порядке применения пункта 2 статьи 855 Гражданского кодекса Российской Федерации»») // Рос. газ. - 1997. - 22 нояб.

2. Постановление Конституционного Суда РФ от 31.03.2015 № 6-П по делу о проверке конституционности пункта 1 части 4 статьи 2 Федерального конституционного закона «О Верховном Суде Российской Федерации» и абзаца третьего подпункта 1 пункта 1 статьи 342 Налогового кодекса Российской Федерации в связи с жалобой открытого акционерного общества «Газпром-нефть» // Рос. газ. - 2015. - 3 апр.

3. Постановление Пленума Верховного Суда РФ от 29.11.2007 № 48 «О практике рассмотрения судами дел об оспаривании нормативных правовых актов полностью или в части» // Рос. газ. - 2007. - 2 дек.

4. Общее административное право: учебник / под ред. Ю.Н. Старилова. - Воронеж: ВГУ, 2007. - 848 с.

5. Административный регламент МВД России по предоставлению государственной услуги по выдаче гражданину Российской Федерации разрешения на хранение огнестрельного гладкоствольного длинноствольного оружия самообороны и патронов к нему (без права ношения) : утв. приказом МВД России от 02.05.2012 № 398 (по сост. на 30.12.2014) // Рос. газ. - 2012. - 12 сент.

6. Решение Верховного Суда РФ от 27.11.2012 № АКПИ12-1428 // БВС. - 2013. - № 5. 
DOI: $10.7256 / 1811-9018.2016 .5 .18537$

При цитировании этой статьи сноска на dоі обязательна

Судебная власть

7. Решение Верховного Суда РФ от 14.04.2011 № ГКПИ11-333.

8. Решение Верховного Суда РФ от 26.02.2014 № АКПИ13-1387.

9. Лазарев, В.В. Пробелы в праве и пути их устранения / В.В. Лазарев. - М.: Юрид. лит., 1974. - 184 с.

10. Кауфман, М.А. Пробелы в уголовном праве: понятие, причины, способы преодоления / М.А. Кауфман. - М.: Юрлитинформ, 2007. - 304 с.

11. Постановление Конституционного Суда РФ от 02.02.1998 № 4-П по делу о проверке конституционности пунктов 10, 12 и 21 Правил регистрации и снятия граждан Российской Федерации с регистрационного учета по месту пребывания и по месту жительства в пределах Российской Федерации, утвержденных постановлением Правительства Российской Федерации от 17 июля 1995 года № 713 // Рос. газ. - 1998. - 10 фев.

12. Правила регистрации и снятия граждан Российской Федерации с регистрационного учета по месту пребывания и по месту жительства в пределах Российской Федерации: утв. пост. Правительства РФ от 17.07.1995 № 713 (по сост. на 05.03.2015) // Рос. газ. - 1995. - 27 июля.

13. О внесении изменений и дополнений в некоторые акты Правительства Российской Федерации: пост. Правительства РФ от 14.08.2002 № 599 // Рос. газ. - 2002. - 21 авг.

14. Административный регламент предоставления Федеральной миграционной службой государственной услуги по регистрационному учету граждан Российской Федерации по месту пребывания и по месту жительства в Российской Федерации: утв. приказом ФМС России от 11.09.2012 № 288 (по сост. на 19.01.2015) // Рос. газ. - 2013. - 17 апр.

15. Апелляционное определение Судебной коллегии по гражданским делам Иркутского областного суда от 13.08 .2014 по делу № 33-6574/2014.

16. Решение по делу № 12-62/2015 / Архив Лаишевского районного суда Республики Татарстан.

17. Постановление по делу № 12-451/2012 / Архив МС СУ № 1 г. Вышнего Волочка Тверской области.

18. Решение Верховного Суда РФ от 28.12.2009 № ГКПИ09-1543.

19. Апелляционное определение Судебной коллегии по гражданским делам Ульяновского областного суда от 09.06 .2015 по делу № 33-2350/2015.

\section{References (transliterated):}

1. Lazarev, V.V. Probely v prave i puti ikh ustraneniya / V.V. Lazarev. - M.: Yurid. lit., 1974. - 184 s.

2. Kaufman, M.A. Probely v ugolovnom prave: ponyatie, prichiny, sposoby preodoleniya / M.A. Kaufman. - M.: Yurlitinform, 2007. $-304 \mathrm{~s}$. 